\title{
Mecanismos y fases de construcción orogénicos del frente oriental andino $\left(36^{\circ} \mathrm{S}\right.$, Argentina)
}

\author{
Juan Álvarez Cerimedo ${ }^{1}$, Darío Orts ${ }^{1}$, Emilio Rojas Vera ${ }^{1}$, Andrés Folguera ${ }^{1}$, Germán Bottesi² $^{2}$, \\ Víctor A. Ramos ${ }^{1}$
}

\begin{abstract}
${ }^{I}$ Laboratorio de Tectónica Andina, Instituto de Estudios Andinos-Universidad de Buenos Aires (UBA), CONICET, Departamento de Ciencias Geológicas, Facultad de Ciencias Exactas y Naturales (UBA). Intendente Antonio Güiraldes (S/N), Pabellón II, Ciudad Universitaria, Capital Federal, Buenos Aires (1428), Argentina. juanskt@hotmail.com; dlorts@yahoo.com;.erv081@yahoo.com.ar; andresfolguera2@yahoo.com.ar; andes@gl.fcen.uba.ar 2 Yacimientos Petroliferos Fiscales (YPF) S.A. Reservoir Manager for Unconventionals, Macacha Güemes 515-CP 1106, Capital Federal, Buenos Aires, Argentina. german.bottesi@ypf.com
\end{abstract}

\begin{abstract}
RESUMEN. El frente oriental andino a los $36^{\circ} \mathrm{S}$ posee características distintivas que van desde un desarrollo longitudinal oriental anómalo, definido por el levantamiento de una serie de estribaciones precordilleranas en el sur mendocino, hasta la ocurrencia de amplias secuencias volcánicas interpretadas como de intraplaca del Oligoceno Superior al Mioceno Inferior. El estudio del área del frente oriental cordillerano a los $36^{\circ} \mathrm{S}$ a partir de extensivo mapeo superficial y datos sísmicos revela una compleja evolución que comprende una fase de exhumación previa a la efusión de los productos de intraplaca oligo-miocenos, una relajación extensional coetánea a los mismos y una última fase de levantamiento en el Mioceno. Esta última fase de exhumación se asocia localmente a sedimentación sinorogénica caracterizada por ciclos granocrecientes con proveniencia desde el área precordillerana en el este. Los mecanismos asociados al levantamiento de las estribaciones del sur mendocino resultan de una interacción entre estructuras de basamento, algunas de las cuales están asociadas a la inversión de fallas normales oligo-miocenas y de despegues en las secuencias pelíticas y yesosas del Cretácico superior y Mioceno.
\end{abstract}

Palabras clave: Andes centrales del sur, Faja Plegada y Corrida de Malargüe, Inversión tectónica, Transiciones frágil-dúctil, Frente orogénico, Cuencas de antepaís.

\begin{abstract}
Mechanisms and deformational stages at the eastern Andean front $\left(36^{\circ} \mathrm{S}\right.$, Argentina). The eastern Andean orogenic front at $36^{\circ} \mathrm{S}$ shows unique attributes when compared to neighbor segments, from an anomalous eastward development of the orogenic front area due to the uplift of a zone of reduced topography in the foothills constituting a pre-Andean belt, to the occurrence of great Late Oligocene to Early Miocene within-plate series. The study of this eastern pre-Andean belt from extensive field mapping and analysis of seismic lines reveals a complex evolution that encompasses a pre-Late Oligocene stage of exhumation prior to the Late Oligocene-Miocene within-plate volcanic products which are coetaneous with an extensional relaxation phase, and one last period of contractional deformation that uplifted the pre-Andean sector in Miocene times. This last stage of orogenic construction is associated with synorogenic strata that show coarsening up sedimentary cycles with an eastward provenance. Contractional mechanisms involved deep ramps rooted into the basement, some of which are linked to inverted Late Oligocene-Miocene normal faults, to shallower detachments located in the Upper Cretaceous and Miocene incompetent layers.
\end{abstract}

Keywords: Southern Central Andes, Malargüe fold and thrust belt, Tectonic inversion, Brittle-ductile transitions, Orogenic front, Foreland basin. 


\section{Introducción}

Los Andes australes muestran, a través de su extensión, estructuras formadas en diferentes fases deformacionales desde el Cretácico Inferior alto hasta el Cuaternario (Groeber, 1929). En general, las estructuras más antiguas han quedado como remanentes dentro de los sectores internos de la faja plegada y corrida, mientras que las más jóvenes se han desarrollado hacia los sectores frontales, mostrando una progresiva expansión lateral de las mismas (e.g., Charrier et al., 2007; Aguirre Urreta et al., 2011; Orts et al., 2012; Mescua et al., 2013).

El frente orogénico de los Andes centrales australes $\left(34^{\circ}-38^{\circ} \mathrm{S}\right)$ al sur del segmento de subducción horizontal pampeano, es identificado como el sitio en el cual se absorben las deformaciones más recientes de la faja plegada y corrida (Fig. 1). Este estudio intenta ejemplificar la complejidad estructural de este sector, así como mostrar en la línea de los estudios ya clásicos realizados en la región (e.g., Manceda y Figueroa, 1995), su policiclicidad a través de la utilización de datos de terreno complementados con información sísmica. De esta forma se mostrará que este sector no se ha construido recientemente en forma exclusiva, sino que conforma una zona que ha constituido el desarrollo frontal de más de una fase deformacional que habría afectado las secuencias mesozoicas a terciarias y su basamento en la región.

El área de estudio se sitúa sobre la vertiente oriental de los Andes, dentro del departamento de Malargüe, a unos $80 \mathrm{~km}$ al sur de la ciudad homónima, en el suroeste de la provincia de Mendoza (Fig. 1). Constituye el extremo más austral de la sierra de Palauco, perteneciente al frente orogénico de la faja plegada y corrida de Malargüe, a unos $350 \mathrm{~km}$ al suroeste de la ciudad capital de Mendoza, y abarca el Cajón de Molina y la zona de Ranquil-Co, a unos $10 \mathrm{~km}$ al este del río Grande e inmediatamente al oeste de Cerro Fortunoso (yacimiento petrolífero explotado actualmente por YPF). Comprende dos estructuras principales, correspondientes a la parte sur del anticlinal de Palauco y su continuación austral en la estructura de Ranquil-Co-El Petiso (Figs. 2, 3) y el anticlinal de la Puntilla de Huincán. Allí se encuentran exhumadas secuencias mesozoicas superiores y terciarias que permiten describir las principales relaciones estratigráficas determinadas en tiempos andinos, ausentes en el sector interno (occidental) de la faja plegada y corrida.

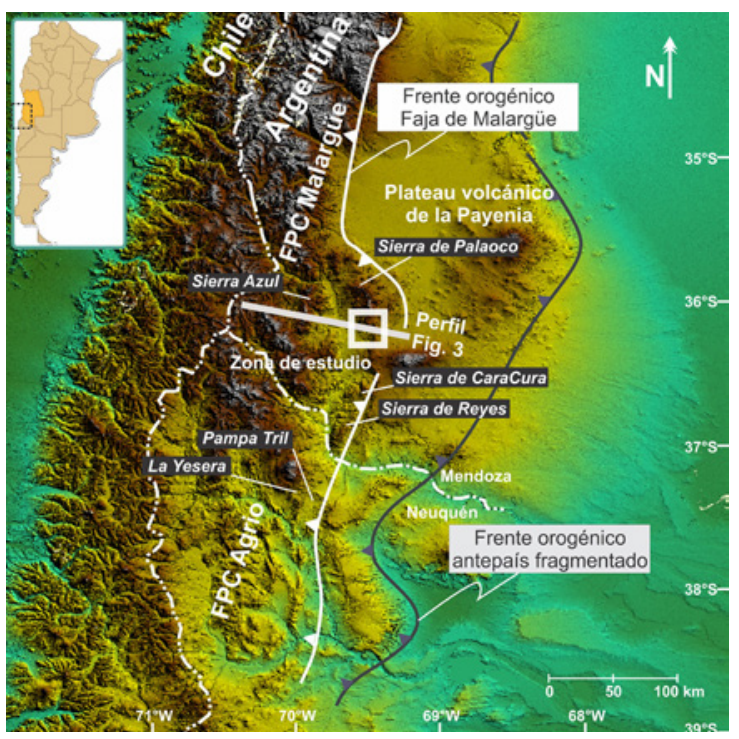

FIG. 1. Ubicación general de la zona de estudio, que abarca aproximadamente $207 \mathrm{~km}^{2}$ del sector surmendocino, y toponimia mencionada en el texto. El modelo de elevación digital permite observar el desarrollo del frente orogénico de la faja plegada y corrida de Malargüe representado hacia el este por las sierras de Palauco, Azul, RanquilCo-El Petiso, Cara Cura y Reyes, donde se inscribe el área de trabajo.

\section{Geología del área de estudio y alrededores}

El frente orogénico en el área estudiada a los $36^{\circ} \mathrm{S}$, a la altura de Ranquil-Co-El Petiso (Figs. 2, 3 ), posee dos sectores bien diferenciados en cuanto a las edades de la estratigrafía aflorante y los estilos deformacionales asociados (Figs. 2, 3). El sector occidental está caracterizado por secuencias paleógenas y neógenas deformadas por un sistema de retrocorrimientos de corta longitud de onda, mientras que el sector oriental posee un mayor nivel de exhumación en el que afloran hasta secuencias cretácicas inferiores en los núcleos de estructuras de gran longitud de onda (Fig. 4).

Particularmente, la unidad aflorante más antigua en la zona de estudio, corresponde al Grupo Bajada del Agrio, observado en el núcleo del anticlinal de Ranquil-Co (Fig. 4).

En la base de esta sucesión, se observa el afloramiento de calizas que corresponden al techo del Miembro La Tosca de la Formación Huitrín (Leanza, 2003). En pequeños bolsones en las márgenes de tributarios del río Triquileu, donde la erosión 


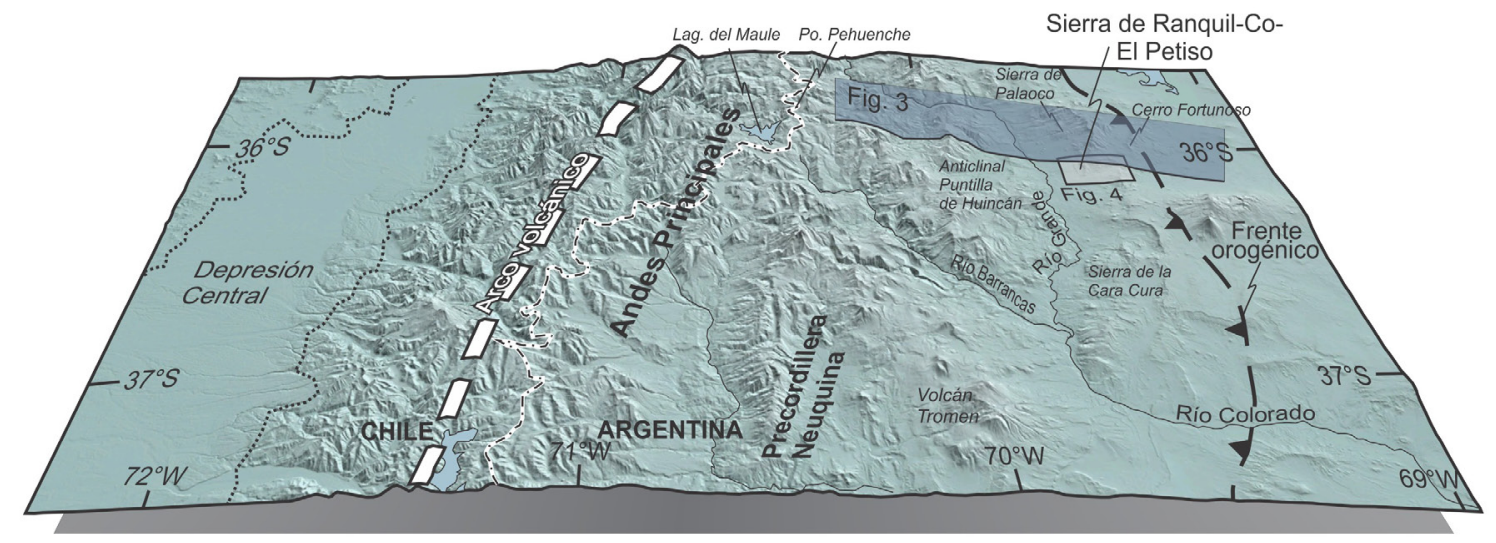

FIG. 2. Principales sistemas montañosos mencionados en el texto desde la depresión central chilena, pasando por el arco volcánico hasta la zona de estudio ubicada en el frente orogénico andino (modelo digital de elevación en perspectiva).

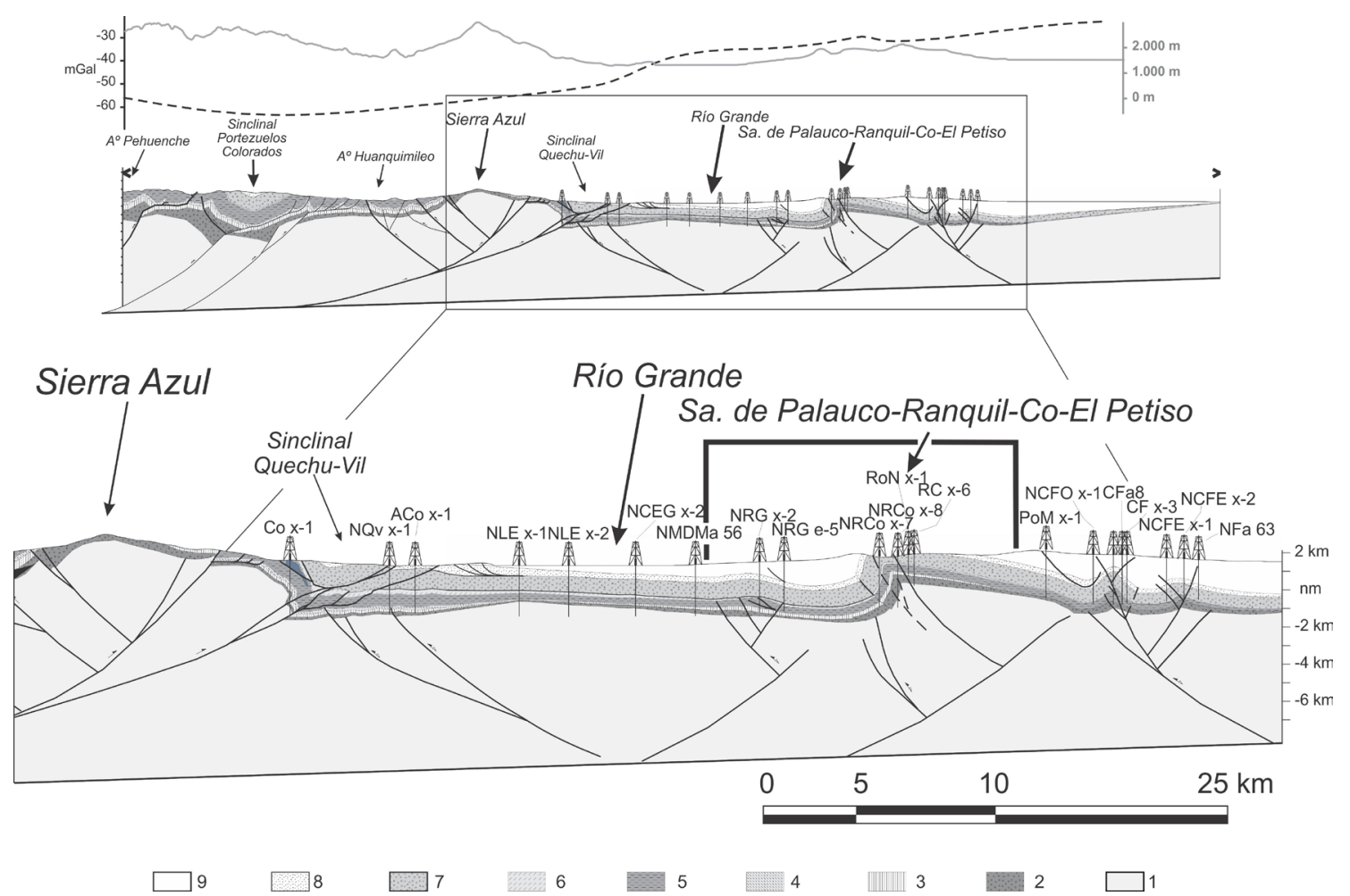

FIG. 3. Sección estructural regional a los $36^{\circ} \mathrm{S}$ que muestra la zona del frente orogénico objeto de este estudio al este del río Grande (modificado de Orts et al., 2012). El semirrecuadro en negro indica la zona específicamente estudiada. La línea gris continua representa la topografía exagerada a través de la transecta, mientras que la línea discontinua en negro indica la anomalía de Bouguer que muestra ser sensible al progresivo afinamiento del relleno sedimentario de la cuenca hacia el este y la reducción de las raíces corticales. Unidades que componen la faja plegada a estas latitudes (leyenda inferior): 1. basamento cristalino; 2. depósitos triásicos de rift; 3. depósitos de sinrift del Jurásico Inferior; 4. evaporitas del Jurásico Superior; 5. secuencias jurásicas superiores a cretácicas inferiores; 6. secuencias evaporíticas del Cretácico Inferior; 7. secuencias del Cretácico superior; 8. secuencias del Cretácico Superior a Eoceno; 9. secuencias del Oligoceno al Mioceno. 
ha expuesto la unidad en el núcleo del anticlinal Ranquil-Co, se reconocieron los depósitos que conforman el techo de la formación y que corresponden al Miembro Salina (Leanza, 2003). En conjunto, esta sucesión representaría la sección basal de la segunda secuencia depositacional carbonática seguida por otra clástico-evaporítica en que puede dividirse al grupo al que pertenece esta unidad.
El Grupo Bajada del Agrio finaliza con los depósitos de la Formación Rayoso, que corresponde a una secuencia dominantemente clástica conformada por material fino atribuida al Miembro Rincón, según lo definido por Leanza (2003).

Por encima se disponen $860 \mathrm{~m}$ de areniscas del Grupo Neuquén en tres ciclos grano- y estrato decrecientes. Las secciones basales, correspondientes

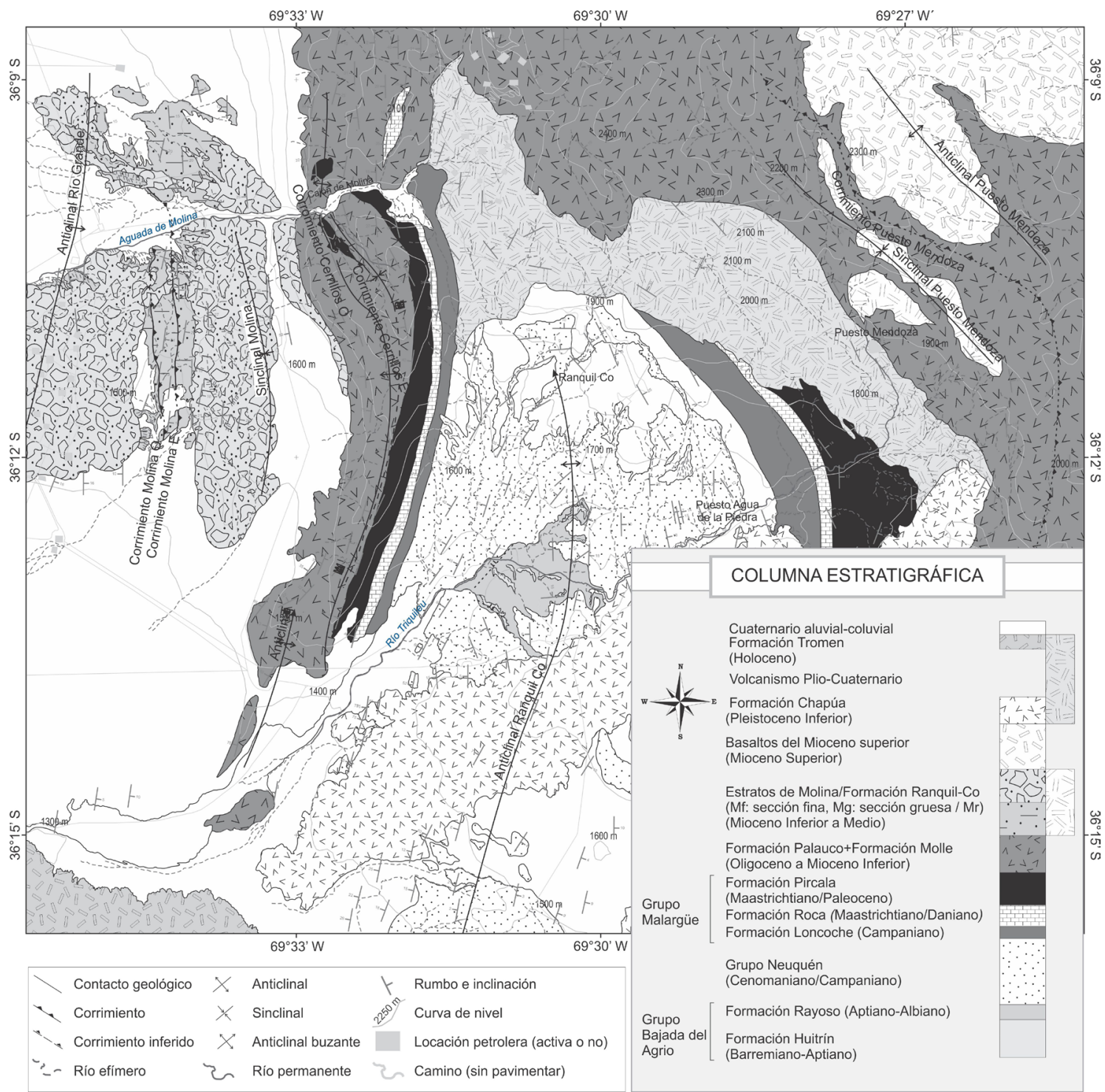

FIG. 4. Mapa geológico del frente orogénico andino (sector precordillerano del sur de Mendoza) en la zona de Ranquil-Co y Cajón de Molina, al sur de la sierra de Palauco y este del río Grande. Nótese un sector occidental conformado por retrocorrimientos y un anticlinal caracterizados por una corta longitud de onda, que transportan en su sector dorsal una pequeña cuenca sinorogénica en el eje de un sinclinal y un sector oriental, caracterizado por estructuras simétricas de mayor longitud de onda. 
al Subgrupo Río Limay, pueden interpretarse como generadas en un paleoambiente de abanico retrogradante o sistema de cursos fluviales entrelazados gravosos, dando paso a uno de tipo arenoso en el Subgrupo Río Neuquén, y donde la porción cuspidal, adjudicada al Subgrupo Río Colorado, puede corresponder a depósitos de planicie de inundación de cursos entrelazados. Esta interpretación de las asociaciones de facies es similar a la realizada por Dicarlo (2005) para los afloramientos del grupo en la zona de Bardas Blancas, quien también observa el desarrollo de sistemas entrelazados en las tres secuencias depositacionales.

Por encima, el Grupo Malargüe comienza con los depósitos de la Formación Loncoche, secuencia sobre la cual González Riga (1999) realiza un perfil estratigráfico de detalle en el flanco oriental del anticlinal de Ranquil-Co. En él distingue dos secciones informales, una inferior clástico calcárea, y una superior, de naturaleza evaporítica. En conjunto, esta secuencia, que muestra un desarrollo de unos $250 \mathrm{~m}$, representa un ambiente continental fluvial y lacustre salino a marino marginal dominado por planicies de mareas (Narciso et al., 2001), lo que indicaría el inicio de la inundación marina atlántica. De acuerdo al estudio preliminar en las paleofloras de la base de esta unidad, que corresponde a la primera aparición de macroflora en el Cretácico superior en los Andes mendocinos, realizado por Álvarez Ramis et al. (2004), pudo interpretarse para el sector de Ranquil-Co una zona palustre o de ribera.

El Grupo Malargüe continúa con los depósitos de la Formación Roca, que se caracterizan por la presencia de calizas esqueléticas de tipo 'packstone' y 'wackestone' con intercalaciones de areniscas calcáreas, areniscas y limolitas. La litofacies de calcáreos esqueléticos es asimilable a una plataforma o rampa carbonática somera de amplio desarrollo, que marca la máxima expansión del mar rocanense en este sector de la cuenca. Según Legarreta et al. $(1985)^{1}$, se podría ubicar el área de suministro clástico hacia el occidente, lo que habría dado como resultado la progradación del sistema continental correspondiente a la Formación Pircala, sobre el dominio marino marginal y de plataforma donde se acumularon las sedimentitas de la Formación Roca.
La litofacies clástica ha permitido inferir un medio de acumulación marino dentro de una plataforma fangosa interna. En el sector de Ranquil-Co el espesor de la Formación Roca oscila entre los 40 y $80 \mathrm{~m}$.

El grupo finaliza con una sucesión de pelitas rojizas a grises, areniscas grisáceas gruesas y arenas tobáceas, correspondiente a la Formación Pircala, que no supera los $200 \mathrm{~m}$ (Legarreta et al., 1985) ${ }^{1}$. El contacto con la unidad subyacente es transicional y el tope está dado por una discordancia regional angular. El ambiente de depositación de estas sedimentitas es eminentemente continental, representando un sistema fluvial distal hasta barreal y cuerpos lagunares someros, con breves interrupciones por inundaciones marinas someras, evidenciadas por la presencia de nanofósiles y foraminíferos (Legarreta et al., 1993).

A continuación se agrupa, bajo la denominación de Formación Palauco, los términos clásticos, y sobre todo volcánicos y volcanoclásticos que suprayacen en discordancia angular al Grupo Malargüe en la zona del Cajón de Molina, parcialmente equivalentes a la Formación del Molle del ámbito andino. Este conjunto había sido agrupado inicialmente en el Palaocolitense de Groeber (1929), pero su edad es determinada en forma precisa a partir de los trabajos de González Díaz (1972a y b, 1979) quien la redefine como Formación Palauco. Esta unidad comienza en su base con un banco de conglomerados conocido en la literatura geológica de la zona con la designación informal de 'Rodados lustrosos', que corresponde a un reducido nivel psefítico de pórfidos sueltos, con clastos de superficie bruñida y color limonita muy característica (Bettini, 1982) y que no supera los $10 \mathrm{~m}$ de espesor (Legarreta et al., 1985) $)^{1}$. A continuación se observa el desarrollo de una sección volcanoclástica que autores previos han interpretado como ignimbrítica, equivalente a las Tobas Quebrada Fiera (Kozlowski et al., 1985², in Silvestro y Atencio, 2009), pero que corresponde a areniscas volcanoclásticas. El mayor desarrollo de la columna está dado por la sección superior (Silvestro y Atencio, 2009) de volcanitas basálticas de $250 \mathrm{~m}$ de espesor, dispuestas en camadas paralelas. Estos basaltos afloran a lo largo del flanco occidental de la sierra de Palauco e inclinan en alto ángulo hacia el oeste. El espesor total de la sección ronda los $280 \mathrm{~m}$.

\footnotetext{
Legarreta, L.; Kokogian, D.A.; Boggeti, D.A.; Kozslowski, E.; Cruz, C.A.; Rebay, G. 1985. Sierra de Palauco. Estratigrafía y estructura, Provincia de Mendoza. Yacimientos Petrolíferos Fiscales (Inédito): 90 p. Buenos Aires.

Kozlowski, E.; Cruz, C.; Rebay, G. 1985. Sierra de Palauco, Provincia de Mendoza. Estructura. YPF (Inédito): 103 p., Buenos Aires.
} 
La Formación Ranquil-Co suprayacente, corresponde a basaltos oscuros anteriormente asignados a la Formación Palauco -Basalto 0- (Legarreta et al., 1985) ${ }^{1}$. En la base de la entidad aparece una sección piroclástica rosada de unos $50 \mathrm{~m}$, seguida por una columna basáltica en la que se observa participación de tobas castaño rosadas (Legarreta et al., 1985) ${ }^{1}$. Silvestro y Atencio (2009) atribuyen a la unidad un espesor de algo más de $550 \mathrm{~m}$. Estas unidades con afinidad volcánica emplazadas sobre el Grupo Malargüe en discordancia angular habían sido datadas inicialmente por González Díaz (1979), pero determinaciones más precisas, recientes, la han circunscrito al intervalo 27-19 Ma (Ramos y Barbieri, 1988; Kay et al., 2006; Cobbold y Rossello, 2003; Silvestro y Atencio, 2009).

En la pequeña subcuenca desarrollada inmediatamente a occidente de la sierra de Palauco, frente al Cajón de Molina (Figs. 3, 4), afloran los Estratos de Molina, definiendo el sinclinal homónimo. Los mismos se asientan en concordancia sobre un nivel tobáceo datado por Silvestro y Atencio (2009) en 18,12 Ma. Esta sucesión clástica granocreciente puede ser dividida en dos secciones (Fig. 5). La sección inferior muestra el desarrollo de facies proximales en contacto con la Formación Palauco, conformando el limbo oriental del sinclinal Molina. Se inicia con fanglomerados correspondientes a flujos de detritos estratificados (Fig. 5a) y continúa con una sucesión clástica conformada por conglomerados basales clasto sostén, con bloques de hasta $1 \mathrm{~m}$ de diámetro máximo, grisáceos, cuya composición es la de la Formación Palauco, con un espesor total de unos $40 \mathrm{~m}$, y continúa con el desarrollo de facies distales, con un espesor mínimo de unos $240 \mathrm{~m}$ en el limbo oriental, conformadas por areniscas finas y pelitas rojas, grises y amarillentas. Intercalado en la base de esta sucesión se ha observado un banco brechoso de unos $6 \mathrm{~m}$ de espesor que ha sido correlacionado con la Formación Molle y que puede ser considerado como base de la unidad, interdigitada con los de la cuenca clástica miocena.

Hacia occidente se observaron afloramientos mejor conservados de las facies distales (Fig. 5b), más finas que en el sector occidental, donde dominan las pelitas con intercalación de niveles de yeso de hasta $40 \mathrm{~cm}$ de espesor, conformando el limbo occidental del sinclinal Molina, donde estas secuencias se encuentran repetidas por una serie de corrimientos (véase sección subsiguiente). La secuencia superior está conformada por al menos tres ciclos granocrecientes (Fig. 5c), correspondientes a gradaciones de arenas gruesas-conglomerádicas a conglomerados mal seleccionados con matriz arenosa. Los clastos alcanzan los $20 \mathrm{~cm}$ en las secciones basales (Fig. $5 \mathrm{~d}$ ) y $50 \mathrm{~cm}$ en las cuspidales (Fig. 5e).

El perfil fue levantado a lo largo de una picada sísmica que atraviesa el limbo oriental del sinclinal de Molina, como se detalla en la figura 5f. Silvestro y Atencio (2009) adjudican a la unidad un espesor de unos $700 \mathrm{~m}$, según lo observado mediante perfilaje de pozos. En este trabajo se calcula un espesor (mínimo) de $611 \mathrm{~m}$.

Por encima se observan acumulaciones de 'Basaltos del Mioceno Superior' (Fig. 4), denominación informal utilizada en este trabajo para suplir aquella de 'Formación Palauco' para estos términos incorrectamente utilizada, compuestas por coladas de basaltos olivínicos y basandesitas oscuras a negras, aglomerados y brechas de basalto, piedra pómez y andesitas e intercalaciones de niveles de tobas blancas dacíticas. El conjunto está atravesado por diques de dacitas y basaltos (Dessanti, 1973; Narciso et al., 2001). Estos basaltos coronan la sierra de Palauco y en el área de estudio se observan afloramientos en el sector nororiental, conformando el núcleo del anticlinal Puesto Mendoza. La unidad ha sido datada en la sierra de Palauco por Silvestro y Atencio (2009) en 8-9 Ma.

Por último, tiene lugar el desarrollo del magmatismo de intraplaca dominado por basaltos alcalinos acaecido en el Plioceno Superior a Cuaternario como parte del desarrollo del 'plateau' volcánico de la Payenia (Fig. 1) (Kay et al., 2006). Este volcanismo se encuentra representado en la zona por las formaciones Chapúa (Pleistoceno Inferior) y Tromen (Holoceno) (Kay et al., 2006; Folguera et al., 2009).

\section{Estructura superficial del frente orogénico a $\operatorname{los} 36^{\circ} \mathrm{S}$}

La zona de estudio, tal como se ha indicado, forma parte del sector frontal de la faja plegada y corrida de Malargüe, caracterizada por la coexistencia de estructuras epidérmicas con grandes estructuras de basamento generadas por la inversión de fallas extensionales de rumbo general NNE relacionadas con el episodio de 'rifting' triásico-jurásico (Zamora Valcarce y Zapata, 2005; Manceda y Figueroa, 1995). Dicha coexistencia, asociada a la propagación de 

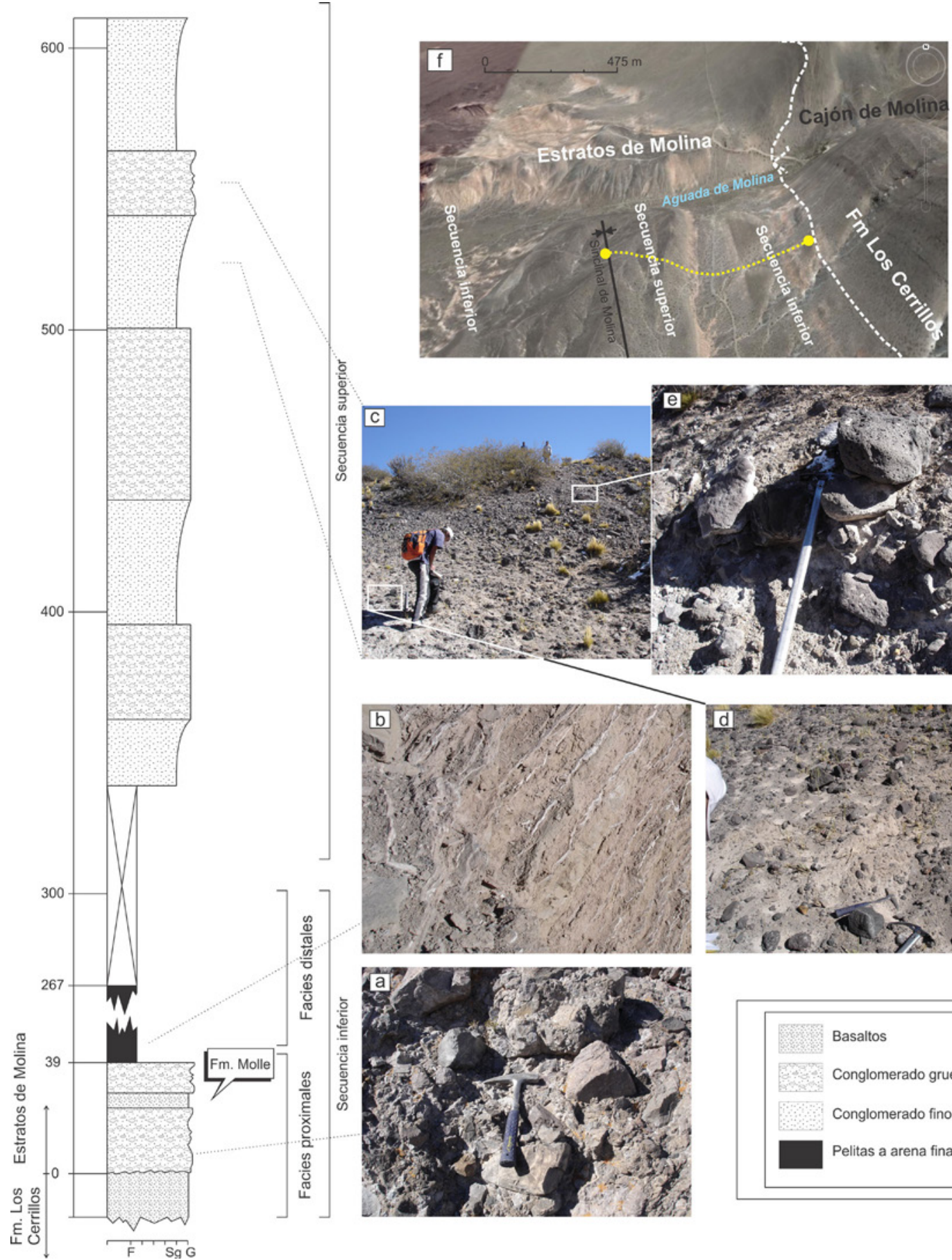

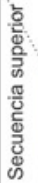
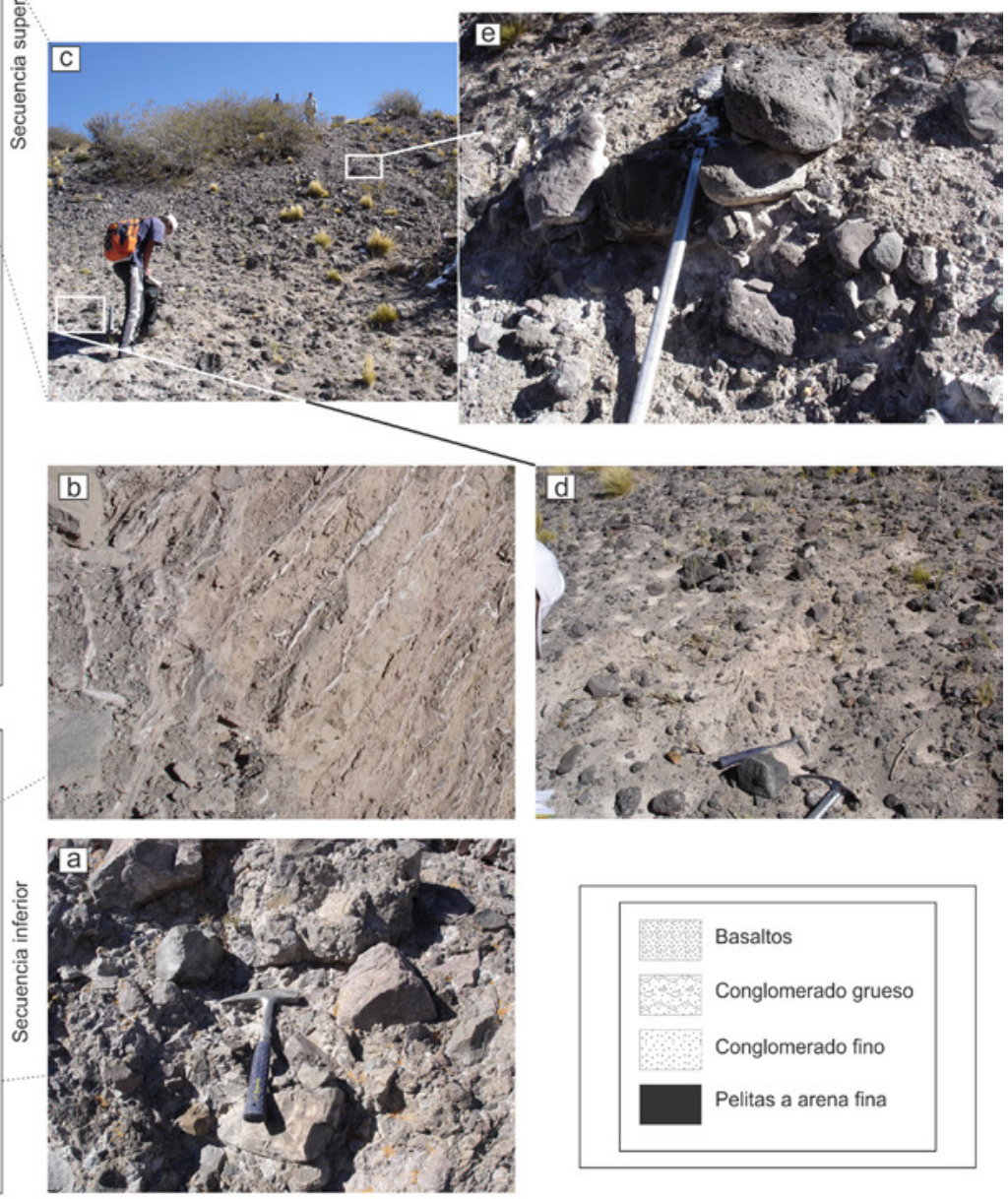

FIG. 5. Columna de los Estratos de Molina levantada en el limbo oriental del sinclinal homónimo. a. Facies proximales de fanglomerados en contacto con la Formación Palauco; b. facies distales, correspondientes a pelitas con yeso; c. ciclo granocreciente conglomerádico; $\mathbf{d}$. detalle de conglomerados finos; e. detalle de conglomerados gruesos; f. ubicación de la columna levantada en línea punteada-de los Estratos de Molina en el limbo oriental del sinclinal de Molina. 
las fallas de basamento en la cubierta sedimentaria, resulta en estructuras de gran complejidad.

Una característica particular del frente orogénico en la zona abarcada por el presente estudio e inmediaciones es su mayor desplazamiento hacia el este respecto del mismo al norte y al sur (Fig. 1). Mientras que a las latitudes aquí analizadas, entre $\operatorname{los} 35^{\circ} 5^{\prime} \mathrm{y}$ $\operatorname{los} 37^{\circ} \mathrm{S}$, alcanza los $69^{\circ} \mathrm{W}$, hacia el norte y hacia el sur se limita a los $70^{\circ} \mathrm{W}$ (Fig. 1). Este desplazamiento del frente orogénico está representado por una serie de estructuras correspondientes a anticlinales asociados a fallas de vergencia oriental que involucran al basamento y en menor medida incluyen deformación epidérmica (Manceda y Figueroa, 1995). Dichas estructuras corresponden a los anticlinales de Sierra Azul, Palauco, Cara Cura, Reyes, Pampa Tril y La Yesera (Figs. 1, 2), dispuestos en tres bloques principales de basamento de rumbo norte.

La estructura más importante de la zona corresponde al braquianticlinal de Ranquil-Co (y su continuación al sur en El Petiso), en posición central, con un rumbo aproximado $\mathrm{N} 20^{\circ} \mathrm{E}$ (Giampaoli et al., 2005). Conforma una estructura asimétrica, producida por una fuerte inclinación de su flanco frontal (occidental), donde se aprecian capas con más de $85^{\circ}$ de inclinación y en parte volcadas, llegando a estar volcado en superficie. El limbo dorsal, tendido, muestra afloramientos de los grupos Neuquén, Malargüe y volcanitas terciarias, con inclinaciones que varían entre los $25^{\circ}$ y los $15^{\circ}$ al este. La exhumación de su núcleo ha permitido la exposición del Grupo Bajada del Agrio, cuya unidad más antigua observada corresponde a la Formación Huitrín.

Este anticlinal, de aparente vergencia occidental, separa una zona occidental, de estructuras pequeñas, de una zona oriental, con estructuras de gran longitud de onda. En oposición a lo que sucede en la mayoría de los sectores de la faja plegada y corrida de Malargüe, la vergencia del anticlinal de Ranquil-Co ha sido interpretada históricamente hacia el oeste, debido a la polaridad inferida para el sector de los hemigrábenes triásico-jurásicos invertidos en subsuelo (Manceda y Figueroa, 1993, 1995).

Al occidente, en el limbo occidental del sinclinal de Molina se observa una serie de corrimientos (Fig. 6), que repiten la secuencia clástica fina a evaporítica de los Estratos de Molina. Se han observado aquí dos láminas, de vergencia occidental y rumbo norte. El sinclinal de Molina habría conformado el receptáculo dentro del cual se desarrollan los
Estratos de Molina, y la contracción generada en su núcleo sería la responsable de las disarmonías locales que dan lugar a los corrimientos de Molina, favorecidos además por la posibilidad de despegue que brinda la composición pelítica de la entidad. Se han sucedido diferentes interpretaciones para la geometría de esta cuenca miocena. Kozlowski et al. $(1985)^{2}$ han interpretado un acuñamiento y una disminución del tamaño de grano de la secuencia hacia occidente, interpretándola entonces como depósitos sinorogénicos asociados al levantamiento de la sierra de Palauco, mientras que Silvestro y Atencio (2009) proponen en oposición un acuñamiento hacia la sierra de Palauco, interpretando a los Estratos de Molina como sinorogénicos a la estructuración de la sierra Azul, hacia el oeste del río Grande (Fig. 2). En este trabajo se propone un desarrollo coherente con el propuesto por Kozlowski et al. $(1985)^{2}$ en cuanto al acuñamiento y disminución del tamaño de grano hacia occidente, con las modificaciones correspondientes a la repetición de la secuencia inferior en el limbo occidental del sinclinal de Molina.

Hacia oriente, entre el sinclinal de Molina y el anticlinal de Ranquil-Co, se desarrollan una serie de estructuras apretadas, de menor escala, englobadas por autores anteriores (Legarreta et al., 1985) ${ }^{1}$ en el limbo occidental de dicho anticlinal. La más occidental consiste en el anticlinal de Molina, de limbo frontal (occidental) volcado y rumbo norte. En este flanco se desarrolla un abanico de inclinaciones menor a $10^{\circ}$ de amplitud, describiendo discordancias progresivas en los basaltos de la Formación Palauco de edad oligocena-miocena inferior (Fig. 7).

Hacia el este, en el núcleo de la estructura, se produce la extrusión de dos láminas de corrimientos. La lámina más occidental (Corrimiento Cerrillos $\mathrm{O}$, $\mathrm{CCO}$ ) repite las volcanitas de la Formación Palauco, mientras que la más oriental (Corrimiento Cerrillos E, CCE) monta a la Formación Pircala sobre la Formación Palauco (Fig. 8), seccionando la última de estas estructuras de menor escala, correspondiente al sinclinal Ranquil-Co, en cuyo núcleo afloran volcanitas de la Formación Palauco.

En la zona oriental se desarrollan el sinclinal y anticlinal Puesto Mendoza, de rumbo NW, entre los que se extiende un corrimiento que repite las volcanitas de la Formación Palauco y secciona al primero generando un pliegue cabalgante. Estas estructuras se recopilan en el esquema de la figura 9. 


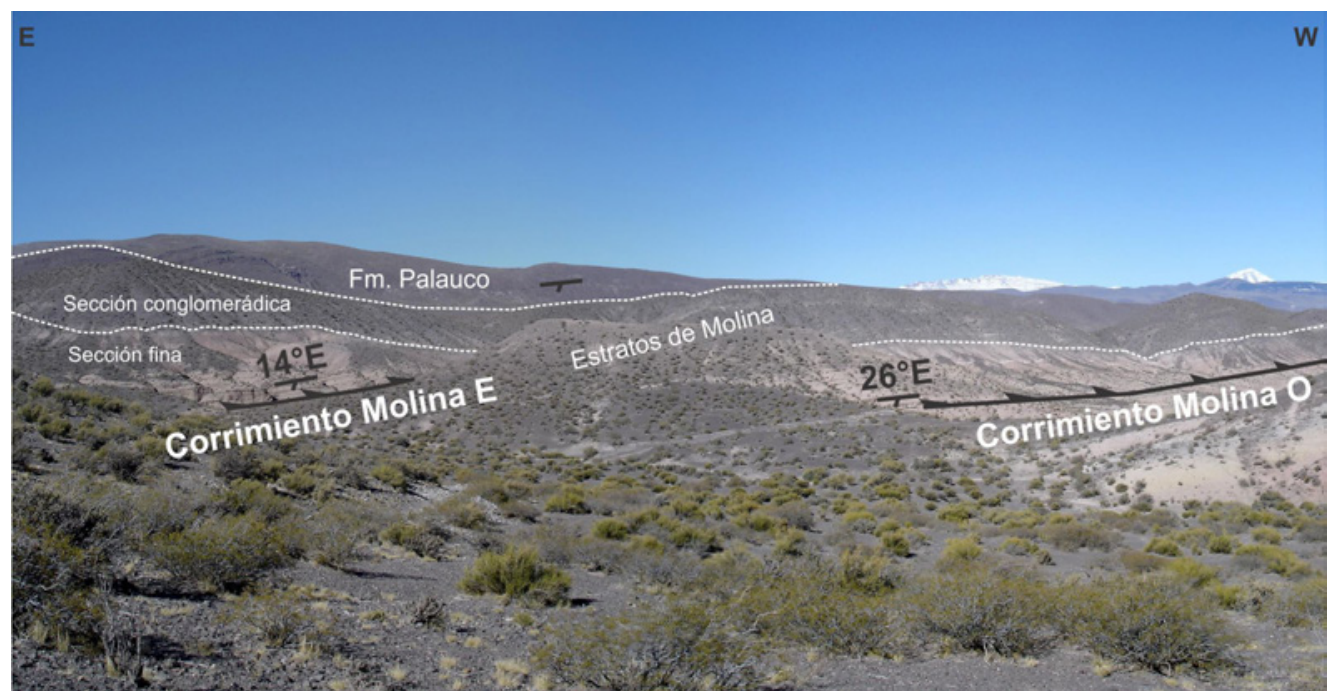

FIG. 6. Vista al sur de las láminas de corrimiento desarrolladas en el limbo occidental del sinclinal de Molina, asociadas a despegues dentro de la secuencia terciaria (véase ubicación en perspectiva regional de figura 9).

FIG. 7. Discordancias progresivas en los bancos de la Formación Palauco del Oligoceno Superior-Mioceno Inferior en el limbo occidental del anticlinal de Ranquil-Co (limbo frontal de la estructura de menor escala del anticlinal de Molina) (véase ubicación en perspectiva regional en figura 9). Hacia occidente las capas disminuyen su edad estratigráfica.
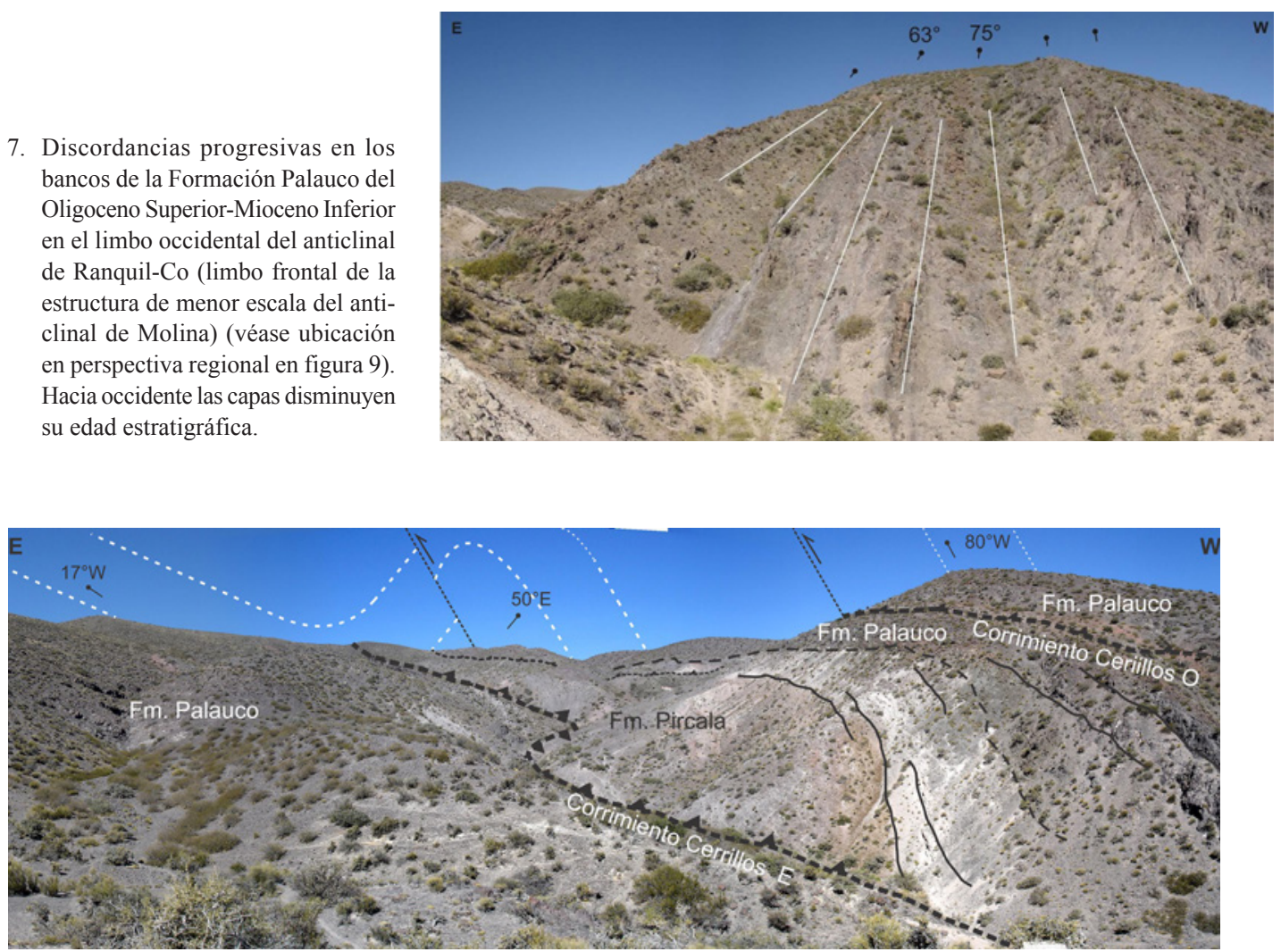

FIG. 8. Corrimiento Cerrillos E (oriental), que exhuma depósitos de la Formación Pircala sobre volcanitas de la Formación Palauco y secciona el sinclinal de Molina, afectando el sector axial del anticlinal de Ranquil-Co-El Petiso (véase ubicación en perspectiva regional en figura 9). Nótese la discordancia angular que se registra entre la Formación Pircala y la Formación Palauco, lo que muestra la fase del Eoceno superior que ha construido parcialmente la zona del frente orogénico. 


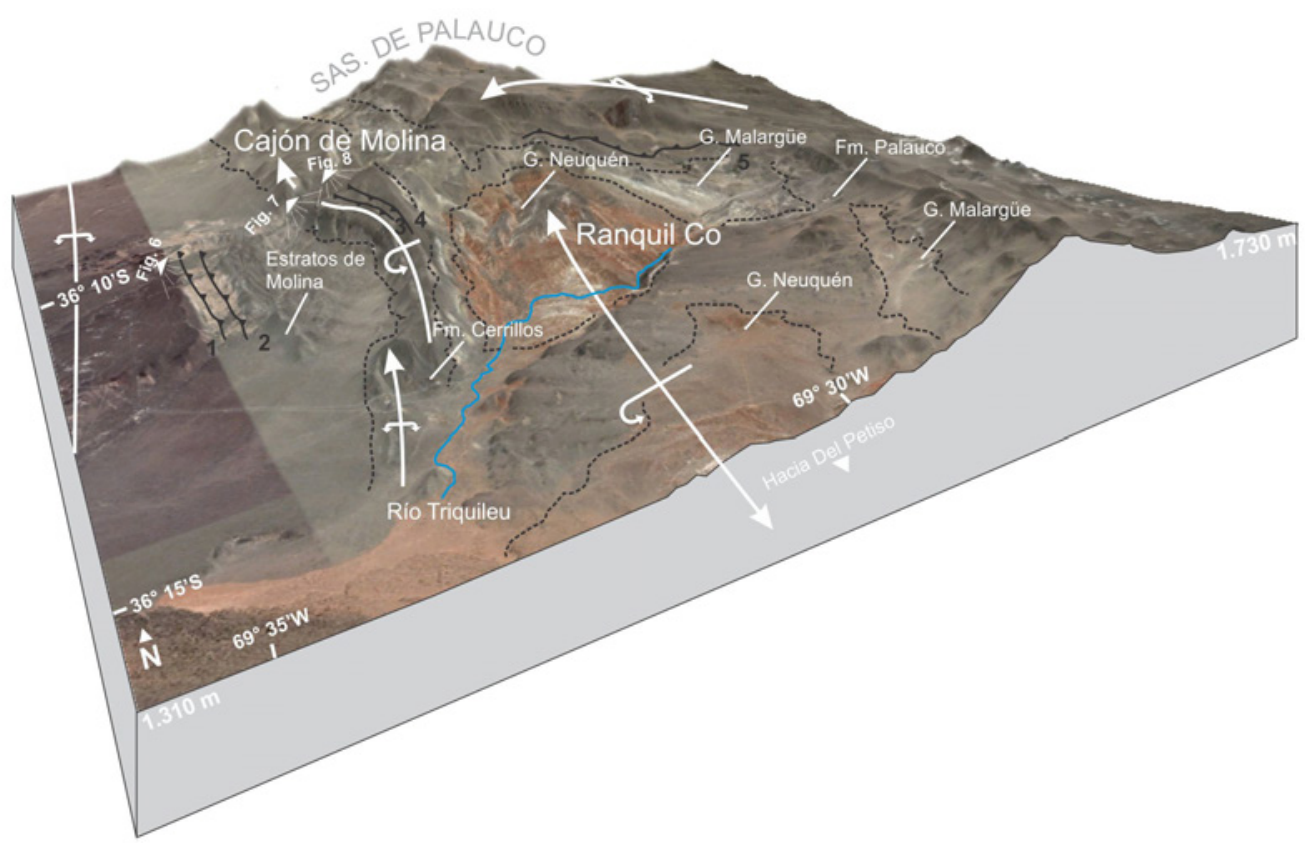

FIG. 9. Estructuras superficiales de la zona estudiada, correspondiente a las estribaciones precordilleranas del sur de Mendoza a $\operatorname{los} 36^{\circ} \mathrm{S}$. De oeste a este: anticlinal Río Grande, anticlinal Triquileu, anticlinal Molina, anticlinal Ranquil-Co-El Petiso, anticlinal Puesto Mendoza. El anticlinal de Molina, desarrollado en el cajón homónimo, conforma una estructura de menor escala, comúnmente englobada en el limbo frontal del anticlinal de mayor envergadura de Ranquil-Co. 1. Corrimiento Molina occidental; 2. Corrimiento Molina oriental; 3. Corrimiento Cerrillos occidental; 4. Corrimiento Cerrillos oriental; 5. Corrimiento Puesto Mendoza.

\section{Estructura en subsuelo del frente orogénico a $\operatorname{los} 36^{\circ} \mathrm{S}$}

Con el objeto de entender los mecanismos subsuperficiales asociados a las estructuras mapeadas en superficie, se interpretaron una serie de imágenes sísmicas 2D de la zona provistas por YPF (Fig. 10) que iluminan aproximadamente tres segundos, penetrando en secuencias terciarias, cretácicas y su basamento.

La línea sísmica 16020 permite ver un anticlinal de gran longitud de onda con un flanco norte poco inclinado, una cresta básicamente horizontal, y una vergencia inferida hacia el sur (Fig. 10). Algunas estructuras menores afectan a este anticlinal generando aparentes relaciones de falla normal en los sectores basales de las secuencias oligocenas a miocenas, hecho evidenciado a partir del engrosamiento de las sucesiones en las inmediaciones de las fallas (Fig. 11).

En la imagen sísmica 16045 (Fig. 12) puede identificarse la estructura anticlinal que coincide en superficie con el anticlinal de Ranquil-Co, y cuya vergencia, occidental, surge claramente a partir de su asimetría superficial, asociada a un flanco occidental de menor longitud. Esta estructura se encuentra segmentada por una serie de fallas de alto ángulo que definen relaciones de falla normal en sucesiones cretácicas a neógenas en su limbo frontal. Las secuencias paleógenas localizadas bajo las del Oligoceno superior se reconocen por su alta reflectividad, mientras que las continentales del Cretácico Superior muestran una baja reflectividad. Como se describió para la imagen sísmica 16020 anterior (Fig. 11), esta imagen muestra que los niveles inferiores de las secciones neógenas (Oligoceno Superior-Mioceno Inferior) poseerían geometría de cuña. Estos hemigrábenes se localizan precisamente en la zona en la que se reconocieron discordancias angulares progresivas dentro de secuencias del Oligoceno-Mioceno Inferior, correspondientes a la Formación Palauco. De esta forma se circunscribe la zona de estructuración extensional oligocena superior-miocena inferior al frente orogénico. Esta deformación extensional asociada a la Formación 


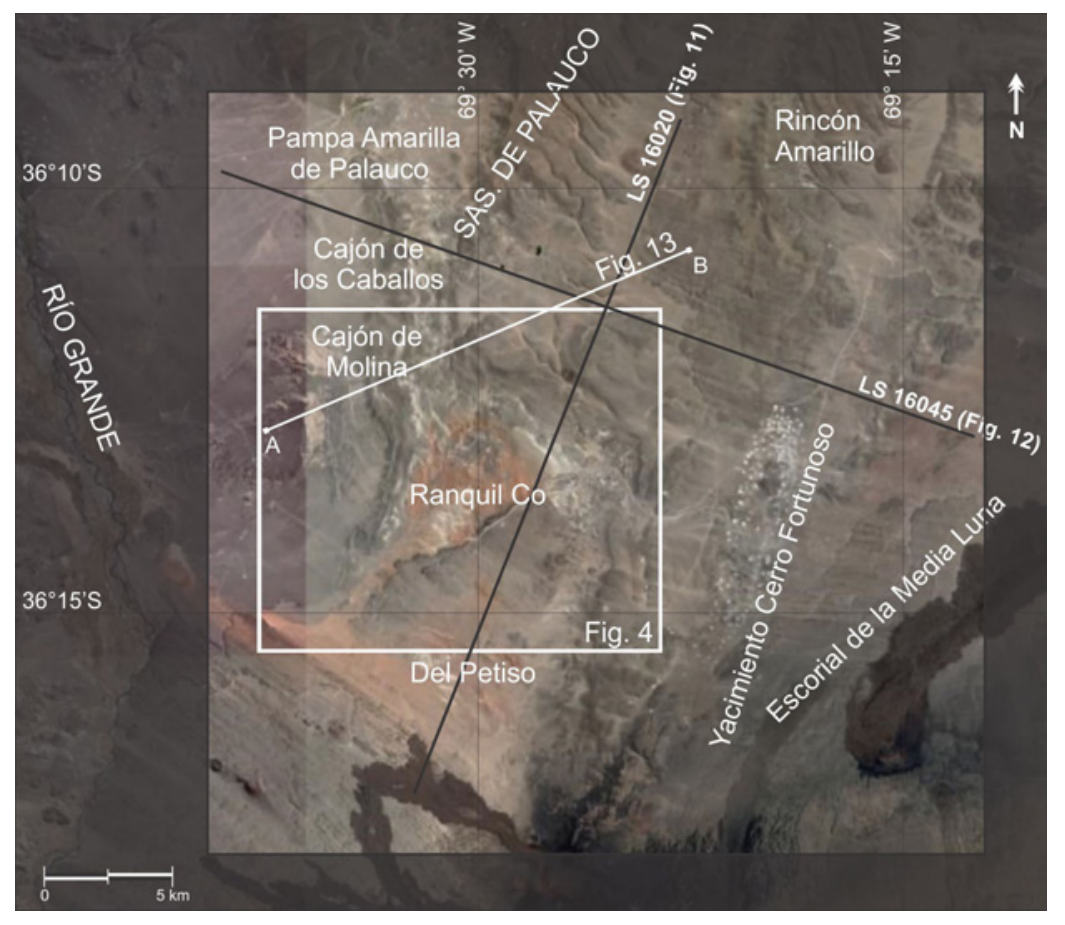

FIG. 10. Posición de las líneas sísmicas interpretadas en relación con la zona estudiada (imagen Ikonos) (en recuadro) y sección estructural.

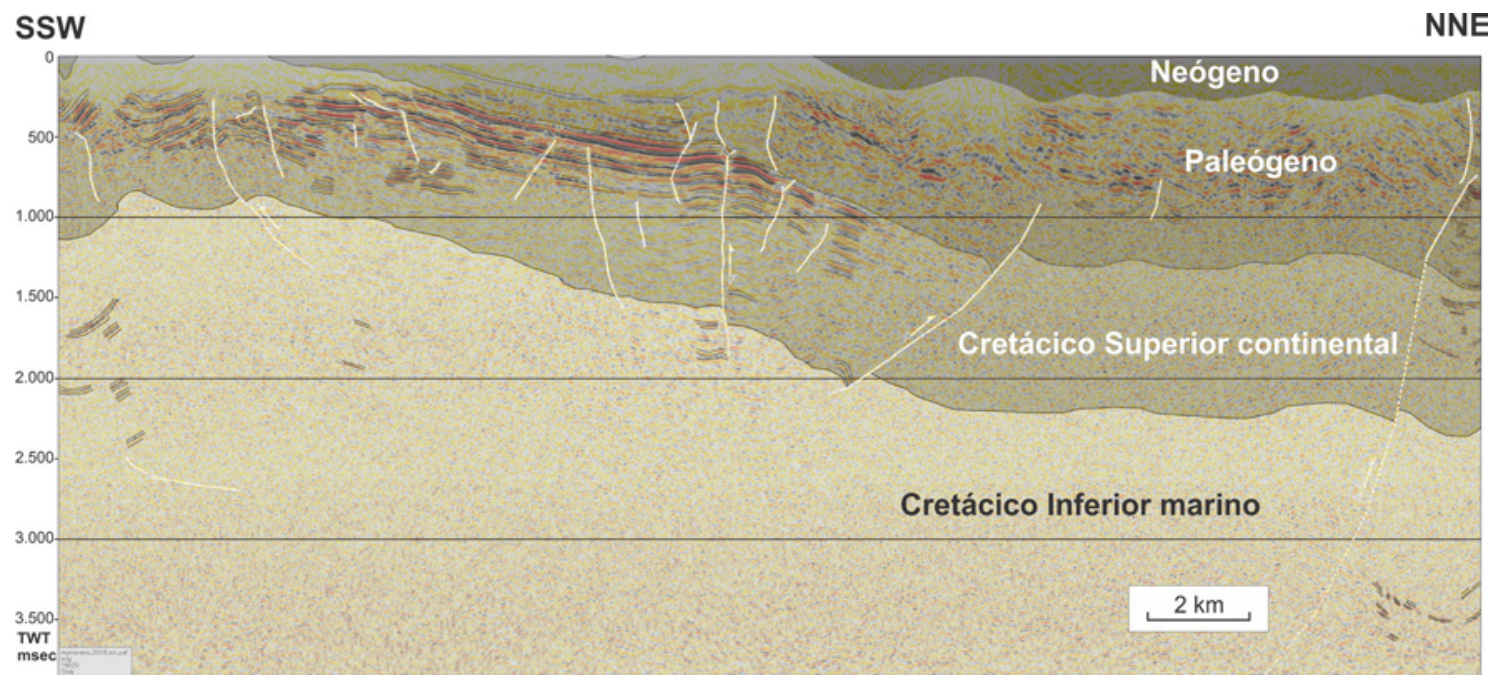

FIG. 11. Interpretación de la línea sísmica 16020 con una orientación NNE (véase su ubicación en la figura 10). Nótese que se interpreta una estructura asimétrica, cuyo mayor relieve estructural se encuentra al sur y posee un limbo norte menos empinado.

Palauco se desarrolla inmediatamente al este del frente orogénico cretácico superior-eoceno, identificado como el límite oriental de la serie de corrimientos que limitan por el occidente al depocentro sedimentario principal de la cuenca de antepaís de Río Grande (Zapata et al., 2008).
Si bien a partir de las líneas sísmicas analizadas surge una aparente vergencia occidental (o noroccidental) en la estructura principal, como ha sido interpretada en trabajos previos, datos de campo muestran que el limbo dorsal (oriental) sufre una fuerte inclinación en el límite oriental de la estructura 


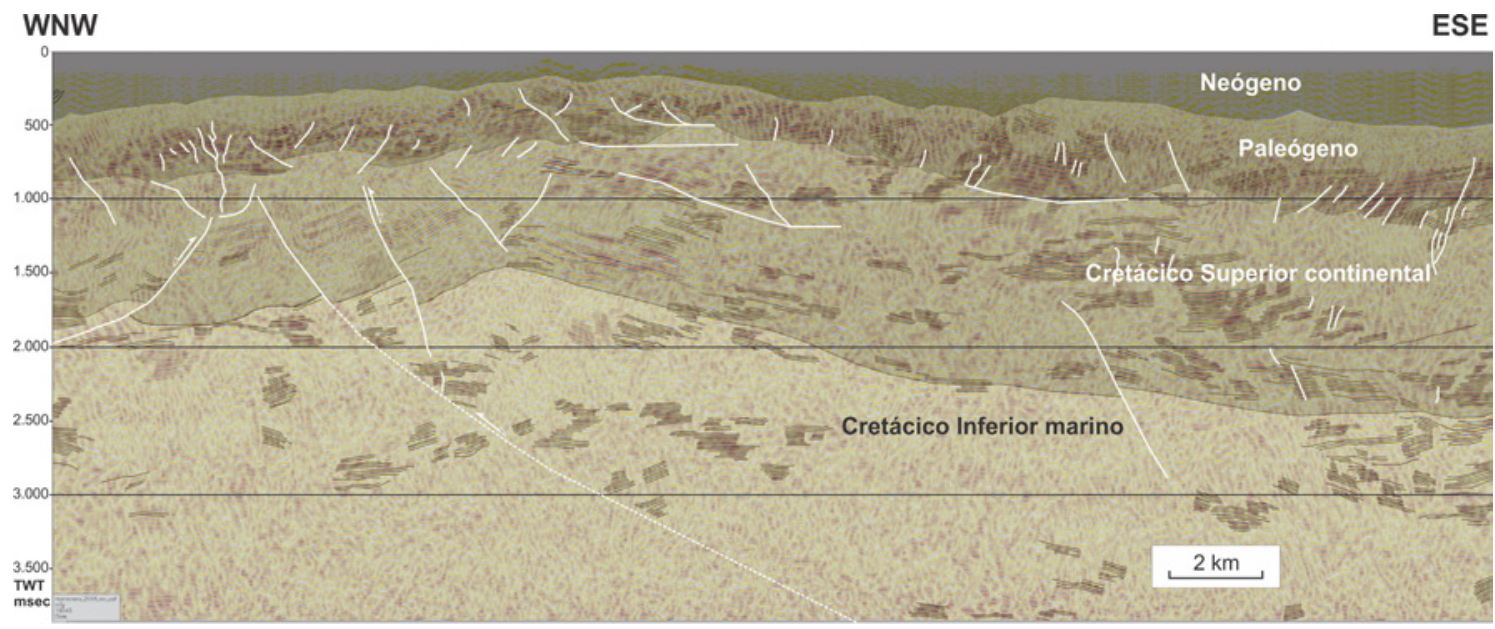

FIG. 12. Interpretación de la línea sísmica 16045 de orientación WNW (véase su ubicación en la Fig. 10). Nótese que el mayor relieve estructural se ubica al oeste y que hacia el este decrece lentamente. Nótese, además, que en el sector occidental-frontal se han interpretado relaciones normales en estratos cretácicos a miocenos inferiores.

(lo que no se observa con claridad en las imágenes sísmicas debido al ruido y la baja resolución en la zona). Este quiebre podría explicarse a través de la existencia de una rampa de basamento con inclinación al oeste, reevaluándose de esta manera la vergencia general de la estructura. La configuración principal estaría definida por acción de un retrocorrimiento que generaría el máximo relieve estructural hacia occidente, pero que habría sido transportado hacia oriente por una rampa que inclina hacia el oeste (Fig. 13).

La figura 13 muestra la sección estructural propuesta para la transecta A-B (véase ubicación en Fig. 10) y su respectiva reconstrucción palinspástica. En el modelo propuesto se interpreta el desarrollo de 5 fallas principales de basamento, con vergencia oeste, de elevada inclinación. Si bien estas estructuras de basamento fueron históricamente adjudicadas a la inversión tectónica de fallas extensionales previas y la vergencia de la sierra de Palauco fue, hasta ahora, interpretada en forma occidental, no está claro el rol de la inversión tectónica en la formación del anticlinal de Ranquil-Co. A partir del hallazgo de discordancias progresivas (sinextensionales) oligocenas-miocenas inferiores en su borde occidental, queda la posibilidad de que esta estructura se hubiera formado por la inversión tectónica de fallas normales asociadas a la cuenca de Palauco. El rol de posibles estructuras triásicas no queda claro a partir del sector analizado.
En este modelo, la serie de retrocorrimientos ('backthrusts') formados, que podrían vincularse a la inversión de fallas extensionales oligo-miocenas, estaría asociada a la inserción de una cuña de basamento con vergencia al este, respetando el transporte andino. De esta manera, la estructura de la sierra de Palauco no solo deja de ser una rareza en el tren de estructuración de la zona con una vergencia opuesta, sino que muestra rasgos comunes a partir de las cuantificaciones de acortamientos medidos para sectores aledaños, como por ejemplo respecto del modelo presentado por Armisen (2009) para la sierra de la Cara Cura o el de Sagripanti et al. (2012) para la sierra de Reyes, apenas unos 30-40 km al sur de la zona analizada. La reconstrucción palinspástica de la sección estructural aquí estudiada arrojó un acortamiento de $2,7 \mathrm{~km}$, lo que equivale a un $12,8 \%$, y un ángulo de cizalla antitética o negativa de $12,4^{\circ}$ (con un error de aproximadamente 1\%). Esta cizalla puede explicarse mediante fricción y deformación entre los bancos durante la estructuración y por errores introducidos en el proceso al utilizar tanto algoritmos de 'Flexural Slip' como de 'Fault Parallel Flow'. Estos valores muestran ser similares a los obtenidos por Armisen (2009) para el sector de la sierra de Cara Cura, que arroja un $10,02 \%$ de acortamiento, correspondiente a 2,49 km, y los obtenidos para la latitud de Ranquil-Co por Giambiagi et al. (2009) de un $12 \%$. 

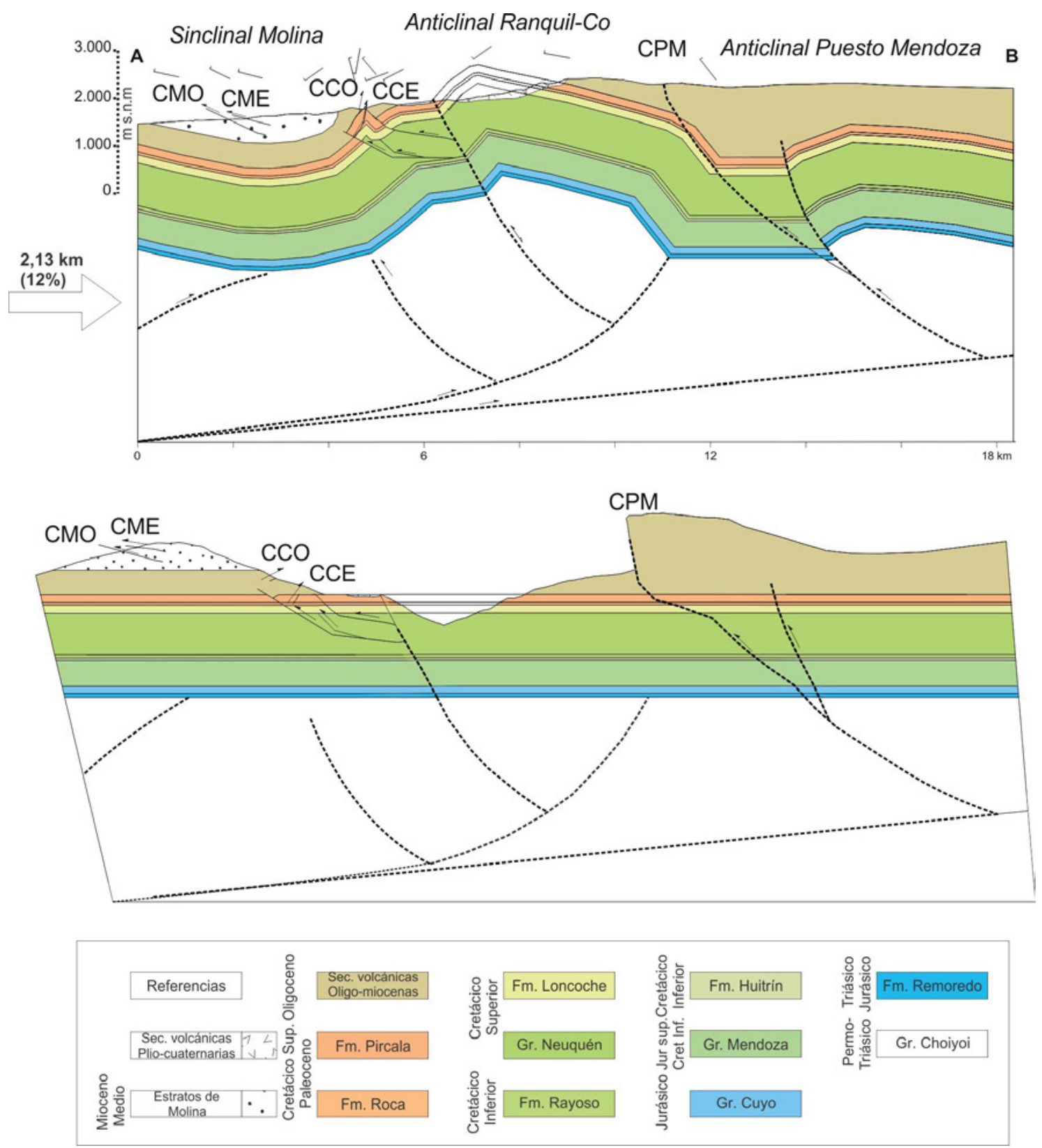

FIG. 13. Sección estructural propuesta para el anticlinal de Ranquil-Co, sector austral de la sierra de Palauco y reconstrucción palinspástica (véase ubicación transecta A-B en Fig. 10). CMO: Corrimiento Molina occidental; CME: Corrimiento Molina oriental; CCO: Corrimiento Cerrillos occidental; CCE: Corrimiento Cerrillos oriental; CPM: Corrimiento Puesto Mendoza.

\section{Evolución del sector frontal de los Andes Cen- trales Australes}

La estructura general del frente orogénico andino a los $36^{\circ} \mathrm{S}$ muestra el desarrollo de mecanismos complejos, con antinclinales de gran escala que estarían asociados a despegues en el basamento y que se transmiten a la cubierta sedimentaria, dando lugar a la generación de estructuras epidérmicas, con despegues en la base del Grupo Neuquén, la 
Formación Roca, y el Mioceno evaporítico (Zamora Valcarce y Zapata, 2005; Silvestro y Atencio, 2009; Sagripanti et al., 2012).

La reconstrucción palinspástica de la sección estructural arrojó un acortamiento de $2,13 \mathrm{~km}$, lo que equivale a un $12 \%$. Estos valores son coherentes con los obtenidos por trabajos previos llevados a cabo en zonas aledañas (Sagripanti et al., 2012).

Las discordancias progresivas observadas en el limbo occidental del anticlinal de Molina permiten interpretar el desarrollo de fallamiento extensional que controla variaciones de espesor de las secciones del Oligoceno Superior-Mioceno Inferior. De esta manera, la sección correspondiente a la Formación Palauco sería una cuenca extensional desarrollada en el antepaís andino-frente orogénico, parcialmente coetánea de la cuenca de Cura Mallín desarrollada sobre el sector interno orogénico a las mismas latitudes (Suárez y Emparán, 1995; Radic, 2010).

La estructura que conforma el sector precordillerano al este del frente emergente de la faja de Malargüe, a estas latitudes se ha desarrollado principalmente
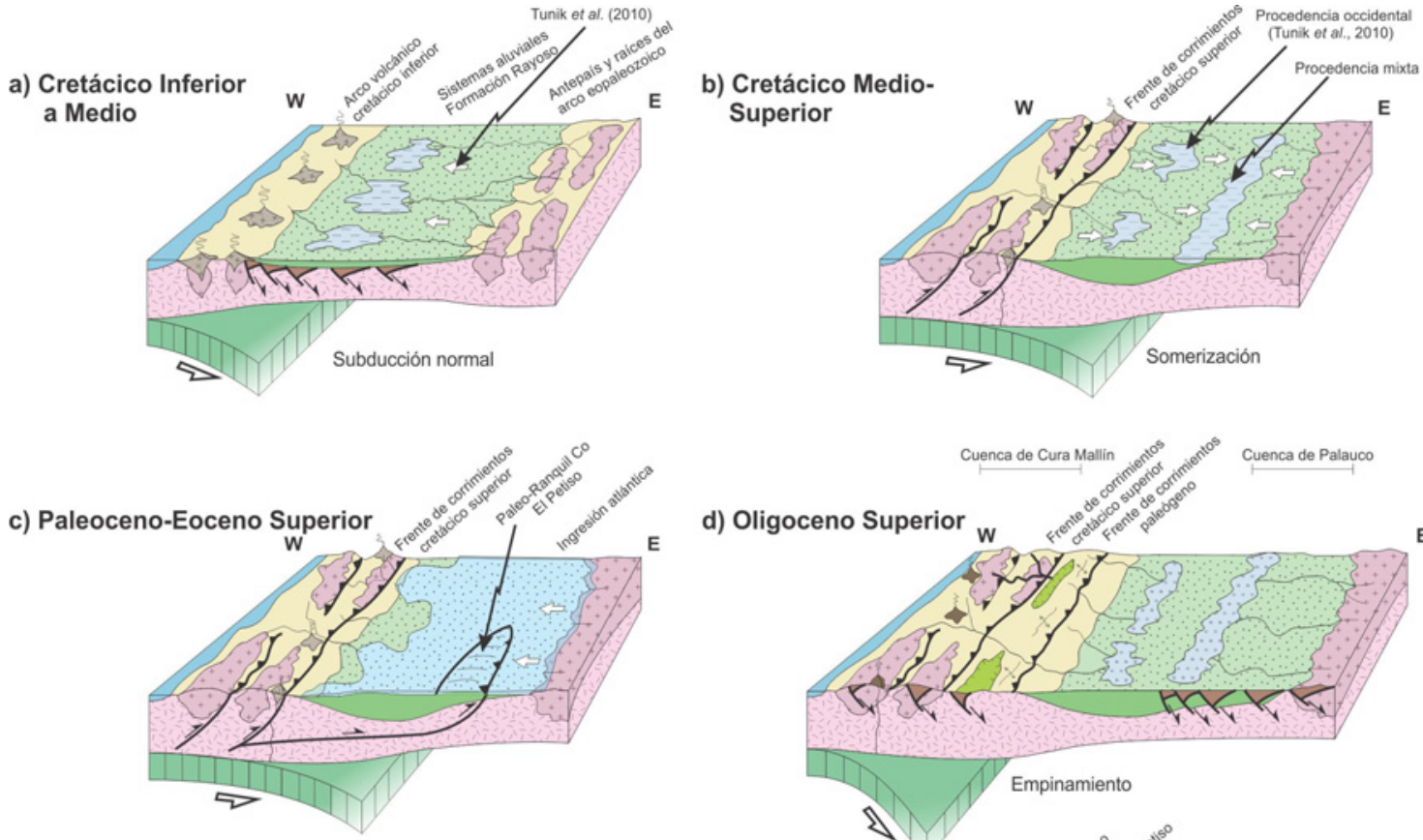

d) Oligoceno Superior

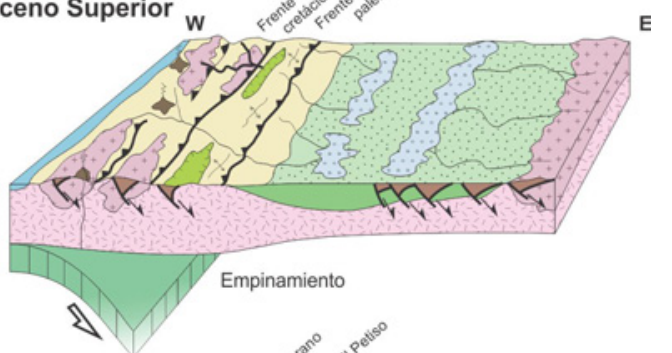

e) Mioceno Medio-Superior

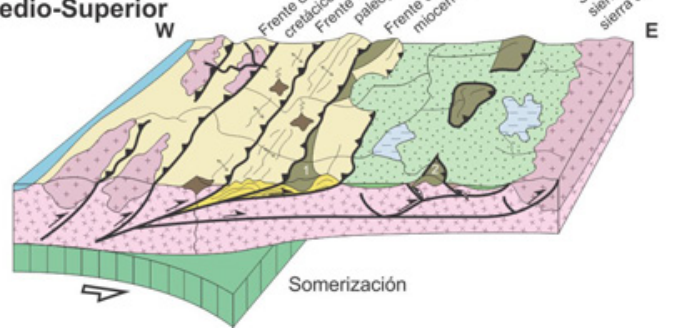

FIG. 14. Evolución tectónica del área del retroarco surmendocino durante los últimos 120 Ma. Nótese la acción de dos fases de construcción orogénica en el Cretácico Superior para la Faja de Malargüe (b) y Eoceno superior para el área del sector precordillerano, al este del frente orogénico emergente respectivamente. Estas fases fueron separadas por una fase de relajamiento extensional en el Oligoceno Superior-Mioceno Inferior (d), asociada a la formación de la cuenca de Palauco en el frente orogénico y a la cuenca de Cura Mallín en el sector oriental fuera del área de estudio. La fase del Mioceno superior (e) reestructura íntegramente el frente orogénico y provoca fallas fueras de secuencia en el sector interno occidental. 
durante el Mioceno Inferior a Medio, hecho evidenciado a partir de materiales sinorogénicos con un aporte oriental, posteriormente canibalizados por el alzamiento del sector. Estos materiales corresponden a los Estratos de Molina que conforman una serie de ciclos granocrecientes con aporte de las volcanitas de la Formación Palauco. Sin embargo, este sector exhuma una discordancia angular entre estratos de la Formación Pircala pertenecientes al Grupo Malargüe y aquellos pertenecientes a la Formación Palauco, lo que implica un pulso de estructuración probablemente circunscrito al intervalo PaleocenoEoceno Superior.

De esta manera se propone la siguiente evolución para el sector precordillerano estudiado (Fig. 14): a. En el Cretácico Inferior las raíces del arco neoproterozoico-eopaleozoico desarrollado en el antepaís constituyen la principal fuente de detritos para la Formación Rayoso (Tunik et al., 2010) a partir de su exhumación inicial en el Paleozoico superior. b. En el Cretácico Superior el desarrollo de la faja plegada y corrida es coetáneo con el desarrollo del Grupo Neuquén, con aporte mixto en la zona de estudio (Tunik et al., 2010). c. Hacia el límite entre el Mesozoico y el Cenozoico se reconfiguran las áreas de aporte con el advenimiento de la ingresión marina procedente del este, correspondiente a los depósitos del Grupo Malargüe. La zona precordillerana ha sido cubierta en su totalidad por esta ingresión, mientras que hacia el oeste del río Grande la misma no ha superado los contrafuertes andinos (Fig. 14) (Aguirre Urreta et al., 2011). De esta manera se infiere que el sector precordillerano es finalmente un rasgo desarrollado postransgresión del Grupo Malargüe, probablemente exhumado inicialmente en el Paleoceno-Eoceno Superior. d. En el Oligoceno superior, tal como se ha descrito, una fase extensional se superpone a la morfología contraccional correspondiente a la fase previa. Así, la extensión eocena superior y oligocena de la cuenca de Abanico o la extensión un poco más tardía algo más al sur, en lo que se denomina la cuenca de Cura-Mallín (Radic et al., 2002; Flynn et al., 2008; Radic, 2010), en Chile central, tendrían su correlato hacia este sector en el antepaís. e. La reactivación de la faja plegada y corrida y en particular del sector precordillerano genera la inversión de los depocentros oligocenosmiocenos inferiores y quizás triásicos en el ámbito interno tanto en el Cretácico Superior-Eoceno como en el Mioceno Superior.

\section{Conclusiones}

La zona estudiada se enmarca en una región en la que el frente Andino se encuentra desplazado hacia el este como consecuencia del levantamiento del sector precordillerano en el sector del frente orogénico. Aquí se distingue un período de exhumación pre-Oligoceno tardío, seguido por una fase de relajación extensional circunscrita al área del frente orogénico.

El último estadio se corresponde con un segundo período contraccional en el Mioceno superior que elevó una serie de estructuras en el área precordillerana, asociada con estratos sinorogénicos que describen ciclos sedimentarios granocrecientes con una procedencia oriental. Los mecanismos de deformación compresiva comprenden desde rampas enraizadas en el basamento (algunas de las cuales se asociarían a la inversión de fallas normales oligo-miocenas) a despegues someros en las capas incompetentes del Cretácico y Mioceno.

$\mathrm{Si}$ bien las estructuras de basamento asociadas al anticlinal de Ranquil-Co fueron históricamente adjudicadas a la inversión tectónica de fallas extensionales previas, y la vergencia de la sierra de Palauco fue hasta ahora interpretada en forma occidental, no está claro el rol de la inversión tectónica en la formación del anticlinal de Ranquil-Co. A partir del hallazgo de discordancias progresivas (sinextensionales) oligocenas-miocenas inferiores en su borde occidental, queda la posibilidad de que esta estructura se hubiera formado por la inversión tectónica de la cuenca de Palauco.

La reconstrucción palinspástica de la sección estructural estudiada arrojó un acortamiento de $2,7 \mathrm{~km}$ acumulados a través de las dos fases contraccionales mencionadas, lo que equivale a un $12,8 \%$, valores coherentes con trabajos previos llevados a cabo a través del frente orogénico.

\section{Agradecimientos}

Se agradece a los revisores de este trabajo, R. Charrier y T. Zapata, cuyas críticas han ayudado a mejorar este trabajo, así como la tarea del editor M. Suárez. Se agradece a la empresa Yacimientos Petrolíferos Fiscales (YPF) S.A. (Argentina) por el suministro de información sísmica y por el financiamiento parcial de los trabajos de campo en el marco de la Tesis del primer autor. Este proyecto ha sido financiado parcialmente con el PIP 112-200801-00016 'La zona subhorizontal de la Payenia y la evolución del 
retroarco neuquino entre $34^{\circ}$ y $38^{\circ} \mathrm{S}^{\prime}$ y los proyectos PIP 11220110100506 UBACYT 20020110100019. Esta es la contribución R-90 del Instituto de Estudios Andinos Don Pablo Groeber. Se agradece, además, a la empresa Midland Valley Ltd. el aporte de la licencia académica del software Move ${ }^{\circledR}$.

\section{Referencias}

Aguirre-Urreta, B.; Tunik, M.; Naipauer, M.; Pazos, P.; Ottone, E.; Fanning, M.; Ramos, V. A. 2011. Malargüe Group (Maastrichtian-Danian) deposits in the Neuquen Andes, Argentina: Implications for the onset of the first Atlantic transgression related to Western Gondwana break-up. Gondwana Research 19: 482-494.

Álvarez-Ramis, C.; Prámparo, M.; Papú, O. 2004. Estudio preliminar de paleofloras cretácicas procedentes de la base de la Formación Loncoche (Mendoza, Argentina). Coloquios de Paleontología 54: 7-14.

Armisen, M. 2009. Geología de la sierra de Cara Cura. Provincia de Mendoza, Argentina. Tesis de Grado (Inédito), Universidad de Buenos Aires, Departamento de Geología: 145 p.

Bettini, F. 1982. Complejos efusivos terciarios, presentes en las Hojas 30c y 32b, Puntilla de Huincán y Chos Malal, sur de Mendoza y norte de Neuquén, Argentina. In Congreso Geológico Latinoamericano, No. 5, Actas 5: 79-114. Buenos Aires.

Charrier, R.; Pinto, L.; Rodríguez, M. 2007. Tectonostratigraphic evolution of the Andean orogen in Chile. In The Geology of Chile (Moreno, T.; Gibbons, W.; editors). Geological Society of London: $414 \mathrm{p}$.

Cobbold, P.; Rossello, E. 2003. Aptian to Recent compressional deformation, foothills of the Neuquén Basin, Argentina. Marine and Petroleum Geology 20: 429-443.

Dessanti, R. 1973. Descripción geológica de la hoja 29b, Bardas Blancas. Provincia de Mendoza. Servicio Nacional Minero Geológico, Boletín 139: 70 p. 1 mapa escala 1:200.000.

Dicarlo, D.J. 2005. Geología en la margen norte del río Grande, Bardas Blancas, provincia de Mendoza. Tesis de Grado (Inédito), Universidad de Buenos Aires, Departamento de Geología: 121 p.

Flynn, J.; Charrier, R.; Croft, D.;Gans, P.; Herriott, T.; Wertheim, J.; Wyss, A. 2008. Chronologic implications of new Miocene mammals from the Cura-Mallín and Trapa-Trapa formations, Laguna del Laja area, south central Chile. Journal of South American Earth Sciences 26: 412-423.
Folguera, A.; Naranjo, J. A.; Orihashi, Y.; Sumino, H.; Nagao, K.; Polanco, E.; Ramos, V.A. 2009. Retroarc volcanism in the Northern San Rafael block ( $34^{\circ}-35^{\circ} 30^{\prime} S$ ), southern Central Andes: Occurrence, age, and tectonic setting. Journal of Volcanology and Geothermal Research 186: 169-185. doi: 10.1016/j. jvolgeores.2009.06.012

Giambiagi, L.; Ghiglione, M.; Cristalini, E.; Bottesi, G. 2009. Características estructurales del sector sur de la faja plegada y corrida de Malargüe $\left(35^{\circ}-36^{\circ} \mathrm{S}\right)$ : distribución del acortamiento e influencia de estructuras previas. Revista de la Asociación Geológica Argentina, 65 (1): 140-153.

Giampaoli, P.; Ramírez, J.L.; Gait, M.A. 2005. Estilo de entrampamiento en la Faja Plegada y Fallada de Malargüe. In Congreso de Exploración y Desarrollo de Hidrocarburos, No. 6, Simposio Las Trampas de Hidrocarburos en las Cuencas Productivas de Argentina: 121-140. Mar del Plata.

González Díaz, E. 1972a. Descripción geológica de la Hoja 30d Payún-Matrú, Provincia de Mendoza. Dirección Nacional de Geología y Minería, Boletín 130: 88 p. 1 mapa escala 1:200.000.

González Díaz, E. 1972b. Descripción geológica de la Hoja 30e Agua Escondida, Provincia de Mendoza. Dirección Nacional de Geología y Minería, Boletín 135: 79 p. 1 mapa escala 1:200.000.

González Díaz, E. 1979. Descripción Geológica de la Hoja 31d, La Matancilla, Carta Geológico-Económica de la República Argentina. Dirección Nacional de Geología y Minería, Boletín 173: 96 p. 1 mapa escala 1:200.000.

González Riga, B. 1999. Hallazgo de vertebrados fósiles en la Formación Loncoche, Cretácico Superior de la provincia de Mendoza, Argentina. Ameghiniana 36 (4): 401-410.

Groeber, P. 1929. Líneas fundamentales de la geología del norte del Neuquén. Dirección General de Minas, Geología e Hidrología 58: 108 p. Buenos Aires.

Kay, S.M.; Burns, W.M.; Copeland, P.C.; Mancilla, O. 2006. Upper Cretaceous to Holocene magmatism and evidence for transient Miocene shallowing of the Andean subduction zone under the northern Neuquén Basin. Geological Society of America, Special Paper 407: 19-60.

Leanza, H.A. 2003. Las sedimentitas huitrinianas y rayosianas (Cretácico inferior) en el ámbito central y meridional de la Cuenca Neuquina, Argentina. Servicio Geológico Minero Argentino (SEGEMAR), Serie Contribuciones Técnicas. Geología 2: 1-31. Buenos Aires. 
Legarreta, L.; Gulisano, C.; Uliana M. A. 1993. Las secuencias sedimentarias jurásico-cretácicas. In Congreso Geológico Argentino, No. 12, y Congreso de Exploración de Hidrocarburos, No. 2, Relatorio 1 (9): 87-114. Mendoza.

Manceda, R.; Figueroa, D. 1993. La inversión del rift mesozoico en la faja fallada y plegada de Malargüe. In Congreso Geológico Argentino, No. 12 y Congreso de Exploración de Hidrocarburos, No. 2, Actas 3: 179-187. Mendoza.

Manceda, R.; Figueroa, D. 1995. Inversion of the Mesozoic Neuquén rift in the Malargüe fold and thrust belt, Mendoza, Argentina. Association of Petroleum Geologists Memoir 62: 369-382, Tulsa.

Mescua, J.; Giambiagi, L.; Ramos, V. 2013. Late Cretaceous uplift in the Malargüe fold-and-thrust belt $\left(35^{\circ} \mathrm{S}\right)$, southern Central Andes of Argentina and Chile. Andean Geology 40 (1): 102-116.

Narciso, F.; Santa María, G.; Zanettini, J.C. 2001. Hoja Geológica 3769-I, Barrancas (Provincia de Mendoza), Programa Nacional de Cartas Geológicas de la República Argentina 1:250.000.

Orts, D.L.; Folguera, A.; Giménez, M.; Ramos, V.A. 2012. Variable structural controls through time in the Southern Central Andes ( $\left.36^{\circ} \mathrm{S}\right)$. Andean Geology 39 (2): 220-241.

Radic, J.P. 2010. Las cuencas cenozoicas y su control en el volcanismo de los complejos Nevados de Chillán y Copahue-Callaqui (Andes del Sur, 36-39º S). Andean Geology 37 (1): 220-246.

Radic, J.P.; Rojas, L.; Carpinelli, A.; Zurita, E. 2002. Evolución Tectónica de la cuenca Terciaria de Cura-Mallín Región Cordillerana Chileno Argentina (36 $\left.30^{\circ}-39^{\circ} 00^{\prime} \mathrm{S}\right)$. In Congreso Geológico Argentino, No. 14, Actas 3: 233-237. Calafate.
Ramos, V.A.; Barbieri, M. 1988. El volcanismo cenozoico de Huantraico: Edad y relaciones isotópicas iniciales, Provincia de Neuquén. Revista de la Asociación Geológica Argentina 43: 210-223.

Sagripanti, L.; Bottesi, G.; Kietzmann, D.; Folguera, A.; Ramos, V.A. 2012. Mountain building processes at the orogenic front. A study of the unroofing Neogene foreland sequence $\left(37^{\circ} \mathrm{S}\right)$. Andean Geology 39 (2): 201-219.

Silvestro, J.; Atencio, M. 2009. La cuenca cenozoica del Río Grande y Palauco: edad, evolución y control estructural, faja plegada de Malargüe. Revista de la Asociación Geológica Argentina 65 (1): 154-169.

Suárez, M.; Emparán, C. 1995. The stratigraphy, geochronology and paleophysiography of a Miocene freshwater interarc basin, southern Chile. Journal of South American Earth Sciences 8 (1): 17-31.

Tunik, M.; Folguera, A.; Naipauer, M.; Pimentel, M.; Ramos, V. A. 2010. Early uplift and orogenic deformation in the neuquén basin: Constraints on the andean uplift from $\mathrm{U}-\mathrm{Pb}$ and $\mathrm{Hf}$ isotopic data of detrital zircons. Tectonophysics 489 (1-4): 258-273.

Zamora Valcarce, G; Zapata, T. R. 2005. Estilo estructural del frente de la faja plegada neuquina a los $37^{\circ} \mathrm{S}$. In Congreso de exploración y desarrollo de Hidrocarburos, No. 6, Archivos electrónicos. Mar del Plata.

Zapata, T.; Zamora Valcarce, G.; Folguera, A.; Yagupsky, D. 2008. Field trip guide: Andean Cordillera and backarc of the south-central Andes $\left(238.5^{\circ} \mathrm{S}\right.$ to $\left.37^{\circ} \mathrm{S}\right)$. In Field trip guides to the Backbone of the Americas in the southern and central Andes: Ridge collision, shallow subduction, and plateau uplift: Geological Society of America Field Guide 13 (Kay, S.M.; Ramos, V.A.; Editors). The Geological Society of America: 23-55.

Manuscript received: March 27, 2013; revised/accepted: June 05, 2013; available online: June 11, 2013. 